\title{
Estudo antropométrico de operadores de motosserra ${ }^{1}$
}

\author{
Luciano J. Minetti ${ }^{2}$, Amaury P. de Souza ${ }^{3}$, José U. Alves ${ }^{4}$ \& Nilton C. Fiedler ${ }^{5}$ \\ 1 Trabalho de pesquisa desenvolvido com recursos financeiros do Conselho Nacional de Desenvolvimento Científico e \\ Tecnológico - CNPq \\ 2 Depto. de Engenharia Florestal - UFV, CEP 36571-000, Viçosa, MG. Fone: (31) 3899-2721. E-mail:minetti@ufv.br (Foto) \\ ${ }^{3}$ Depto. de Engenharia Florestal - UFV. fone: (31) 3899-2465. E-mail: amaurysouza@ufv.br \\ ${ }^{4}$ Depto. de Engenharia Florestal - UFV \\ ${ }^{5}$ Depto. de Engenharia Florestal - UnB, CEP 70910-970, Brasília, DF
}

Protocolo $101-28 / 6 / 2001$

\begin{abstract}
Resumo: Através deste trabalho, objetivou-se estudar, antropometricamente, os operadores de motosserra no corte florestal de Eucalyptus spp. Os objetivos específicos foram: conhecer os padrões antropométricos dos operadores de motosserra, determinar os limites mínimos e máximos das variáveis estudadas e selecionar variáveis correspondentes à dimensão da motosserra para o operador. A coleta de dados foi realizada na empresa de papel e celulose, localizada no Estado de São Paulo. Foram selecionadas 35 variáveis antropométricas para aplicação no estudo e avaliados 85 operadores de motosserra. Verificou-se que a massa média do operador foi de $67,9 \mathrm{~kg}$. 0 percentil $50 \%$ apresenta o valor de 1,705 m para a variável altura do topo da cabeça. O espaço mínimo para introdução da mão no cabo da motosserra, não deve ser inferior a 0,115 m e a profundidade mínima para introdução da mão no cabo da motosserra também não deve ser inferior a 0,088 $\mathrm{m}$.
\end{abstract}

Palavras-chave: corte florestal, ergonomia, antropometria

\section{Anthropometric study of chainsaw operators}

\begin{abstract}
The general objective of this work was to anthropometrically study the chainsaw operators during the forest harvest of Eucalipytus spp. The specific objectives were to find out the anthropometrics patterns of chainsaw operators; to determine the minimum and maximum limits of the variables studied; and to select variables, which correspond to the dimensions of the chainsaw for the operator. Data collection was done at a pulp and paper enterprise located in the state of São Paulo, Brazil. Thirty-five anthropometrics variables were selected for the study. Eighty-five chainsaw operators (totaling $100 \%$ of the operators of the enterprise) were evaluated. The mean weight of the operator was of $67.9 \mathrm{~kg}$. The $50 \%$ presented a value of $1.705 \mathrm{~m}$ for the variable height of the top of the head. The minimum space for the introduction of the hand in the handler of the chainsaw should not be less than $0.115 \mathrm{~m}$. The minimum depth for the introduction of the hand in the chainsaw handler should not be less than $0.088 \mathrm{~m}$.
\end{abstract}

Key words: forest harvest, ergonomy, anthropometry

\section{INTRODUÇÃO}

Antropometria é o campo da antropologia física que estuda as dimensões do corpo humano. Esse estudo se baseia na tomada de medidas como dimensões, movimentos e comprimento dos membros do corpo (Moraes, 1983). Na ergonomia, são encontrados dois tipos de dimensões antropométricas: estáticas e dinâmicas. As dimensões estáticas estão relacionadas com as medidas físicas do corpo parado, enquanto as dinâmicas se relacionam com as medidas do corpo em movimento, ou trabalho.

Para se aplicar corretamente os dados, é importante avaliar os fatores que influenciam os dados antropométricos: raça, etnia, dieta, saúde, atividade física, postura, posição do corpo, vestuário, hora do dia etc. (Iida, 1990).

As medidas antropométricas de um(a) operador(a) servem para adequar os meios de produção, quando se utiliza a motosserra ou qualquer outra ferramenta ou instrumento. Segundo Moraes (1983) quando essas máquinas ou equipamentos se adaptam adequadamente ao organismo, sob o ponto de vista dimensional, os erros, os acidentes, o desconforto e a fadiga, diminuem sensivelmente.

O primeiro passo, então, é se obter as medidas antropométricas do(a) operador(a), visando à adaptação do trabalho ao operador, de forma a conseguir uma postura correta, uma posição mais favorável ao corpo e maiores velocidade e precisão 
dos movimentos musculares aumentando, assim, a eficiência dos movimentos dos membros e do operador. As dimensões dos segmentos corporais variam de indivíduo para indivíduo, como também no mesmo organismo, ao longo de sua vida. Não existe nenhum indivíduo cujas dimensões sejam totalmente harmoniosas, isto é, todas elas são componentes de uma média.

O levantamento de dados antropométricos mostra a variabilidade das dimensões de uma população; logo, não podem ser levadas em conta as medidas que se referem a uma população de outra região, com diferentes níveis socio-econômicos, idade e sexo (Barros, 1996).

As medidas antropométricas são dados de bases essenciais para concepção de um posto que satisfaça ergonomicamente os(as) trabalhadores(as), pois só a partir das dimensões dos indivíduos é que se pode definir, de forma racional, o dimensionamento adequado, tanto da máquina de trabalho como da atividade envolvida visando, basicamente, à segurança, à eficiência e ao conforto do trabalhador.

O objetivo principal desta pesquisa foi se estudar, antropometricamente, o operador de motosserra, no corte florestal de eucalipto. Nesse estudo, pretendeu-se: a) conhecer os padrões antropométricos dos operadores de motosserra; b) determinar os limites mínimos e máximos das variáveis estudadas e c) selecionar variáveis correspondentes à dimensão da motosserra para o operador.

\section{MATERIAL E MÉTODOS}

O universo do estudo foi constituído por operadores diretamente ocupados na atividade de corte florestal, em uma empresa de papel e celulose, localizada nas coordenadas $22^{\circ} 35^{\prime} 08^{\prime}$ ' S e 46 58'11' W, numa altitude de $630 \mathrm{~m}$, no Estado de São Paulo. A população estudada era composta por 85 operadores de motosserra, número este que corresponde a $100 \%$ dos operadores de motosserra da empresa.

Foram utilizadas motosserras profissionais da marca Stihl modelo 038, com as seguintes especificações técnicas: cilindrada $61,5 \mathrm{~cm}^{3}$; potência no corte de $3 \mathrm{kw}$; capacidade do tanque de combustível de $0,75 \mathrm{~L}$; capacidade do tanque de óleo lubrificante de $0,45 \mathrm{~L}$ e peso total $8,0 \mathrm{~kg}$.

\section{Seleção de variáveis}

Foram selecionadas 35 variáveis antropométricas, para aplicação no estudo, todas obtidas por medição direta.

Utilizou-se uma nomenclatura de fácil compreensão, usando-se termos específicos da anatomia humana e descrita em relação à posição dos eixos do corpo humano. Os eixos ortogonais podem definir três planos necessários ao posicionamento e direcionamento para descrição do corpo humano: a) plano cardinal mediano, b) plano coronal ou frontal, e c) plano horizontal ou transverso, conforme pode ser visto na Figura 1, em que: a) plano mediano: é um plano imaginário do topo da cabeça até a base do corpo entre os pés, que divide o corpo em direita e esquerda; b) plano coronal ou frontal: é um plano vertical a partir do topo da cabeça até a sola do pé, que intercepta o plano mediano em ângulo reto e divide o corpo em duas partes: ventral e dorsal e c) plano horizontal ou transverso: é um plano que divide o corpo em duas partes: superior e anterior; é perpendicular ao plano mediano e coronal.

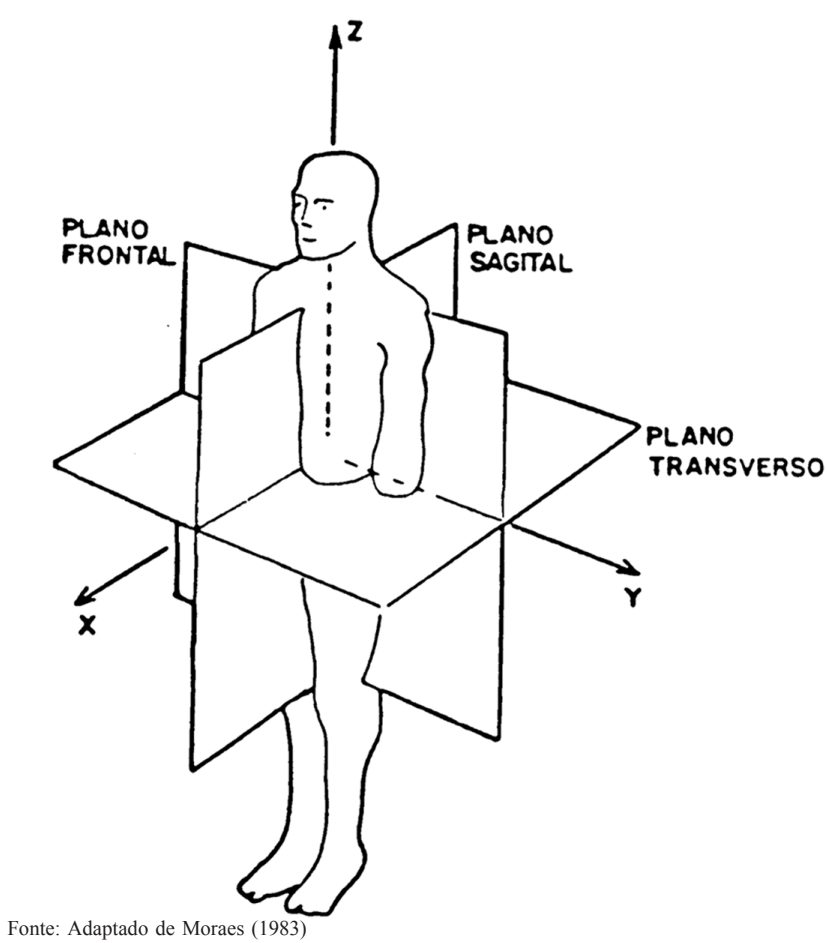

Figura 1. Descrição do corpo humano em planos

\section{Descrição das medidas}

Todas as medidas levantadas nesse estudo foram medidas antropométricas estáticas, isto é, são aquelas relacionadas às dimensões físicas do corpo parado em posições padronizadas. As variáveis selecionadas para o estudo são relacionadas a seguir e as alturas são distâncias verticais a partir do chão, estando o sujeito de pé ou sentado:

- alturas de pé: altura do topo da cabeça; altura do nível dos olhos; altura do ouvido; altura do punho; altura do joelho; altura da espinha ilíaca; altura do tórax; altura do apêndice xifóide; altura do umbigo; altura do mento; altura do ombro; altura do cotovelo e altura entre pernas.

Os alcances são profundidades, alturas ou comprimentos horizontais ao longo do eixo do braço ou da perna. Os alcances se dividem em: frontais, a partir das costas; medidos no plano sagital inferior ou superior, a partir do solo e medidos, no plano transverso, a partir do ombro, correspondendo a um comprimento horizontal:

- alcance inferior máximo: alcance inferior em pega empunhadura; alcance frontal à extremidade do dedo médio; alcance frontal em pega empunhadura e alcance frontal do antebraço à extremidade do dedo médio.

Os comprimentos são distâncias normalmente formadas ao longo do eixo mais longo de um segmento do corpo:

- comprimento do membro superior: comprimento interarticular do ombro ao cotovelo; comprimento interarticular do cotovelo ao pulso; comprimento interarticular do joelho ao tornozelo e comprimento do pé.

As larguras são distâncias horizontais bilaterais:

- largura do quadril e largura do pé.

Os perímetros são distâncias num único plano, em volta do segmento ou da área do corpo:

- perímetro braquial. 
As variáveis da mão foram:

- largura da mão no metacarpo; largura da mão no polegar; largura da mão fechada; comprimento da mão na extremidade do dedo médio; comprimento da mão na extremidade do dedo mínimo; comprimento da palma da mão; comprimento da mão na extremidade do polegar e comprimento da mão na base do polegar.

\section{Técnica e instrumental de medição}

Neste estudo, foram realizadas somente medidas estáticas do operador. As medidas foram tomadas em três locais por uma única equipe de medição, adotam-se uma técnica que atendia a uma precisão suficiente, à agilidade de execução e a um instrumental simples e de baixo custo.

Para realização das medidas antropométricas, utilizou-se a técnica de "Morant", adaptada segundo INT (1988).

Utilizou-se um painel fixo, composto por duas paredes totalmente lisas, formando um ângulo de $90^{\circ}$ com o piso. Nas paredes, foram aplicadas tramas de papel milimetrado, medindo $2,20 \mathrm{~m}$ de altura por $1,10 \mathrm{~m}$ de largura. $\mathrm{O}$ papel foi quadriculado com uma trama de $0,005 \mathrm{~m}$ cada um para se proceder à leitura das dimensões antropométricas de cada operador.

Para a largura do corpo e dos segmentos interarticulares dos membros, utilizou-se medição por meio de uma régua de alumínio, graduada com precisão de $0,001 \mathrm{~m}$, fixada uma barra de alumínio em uma de suas extremidades, formando um ângulo de $90^{\circ}$ com a régua. Para se efetuar a medida, empregou-se um esquadro corrediço de acrílico também formando um ângulo de $90^{\circ}$ com a régua.

Os operadores foram medidos com o mínimo de roupa possível. Os instrumentos utilizados apenas tocaram o indivíduo, fazendo uma pressão homogênea e constante contra o corpo.
Para as medidas em pé, o operador permaneceu ereto, com a cabeça orientada para o plano aurículo-orbitário; as costas, as nádegas, os ombros e os calcanhares, tocavam a superfície de apoio, levemente. Nesse tipo de medida, os calcanhares e os joelhos devem estar juntos. Os braços devem estar relaxados pendendo ao longo do corpo, com a palma da mão paralela à coxa e o polegar para frente e a musculatura descontraída.

Antes da liberação do operador, constatou-se se todos os itens foram preenchidos.

\section{Análise dos dados}

A análise estatística dos dados foi feita mediante o uso de percentis, que é uma separatriz que divide a distribuição em 100 partes iguais, a partir do menor para o maior, em relação a algum tipo específico de dimensão corporal. Os percentis utilizados nos valores indicados para as variáveis estudadas foram 5, 50 e $95 \%$.

Uma medida do 5 percentil quer dizer que, apenas $5 \%$ das pessoas que foram medidas no levantamento antropométrico têm dimensões inferiores a este padrão ou, ainda, que $95 \%$ das pessoas desse mesmo levantamento têm dimensões superiores às deste padrão.

\section{RESULTADOS E DISCUSSÃO}

\section{Perfil antropométrico dos operadores}

Os resultados do perfil antropométrico das variáveis estáticas dos operadores de motosserra, encontram-se nas Tabelas 1 e 2, relativos ao indivíduo em pé e ao tamanho da mão, respectivamente; nelas, encontram-se analisados os percentis 5, 50 e 95\%, a média, o desvio-padrão e o coeficiente de variação.

Tabela1. Percentis, média, desvio-padrão e coeficiente de variação do levantamento antropométrico dos operadores (indivíduo em pé)

\begin{tabular}{|c|c|c|c|c|c|c|}
\hline \multirow{2}{*}{ Variável $^{*}$} & \multicolumn{3}{|c|}{ Percentis Encontrados } & \multirow{2}{*}{ Média } & \multirow{2}{*}{$\begin{array}{l}\text { Desvio- } \\
\text { Padrão }\end{array}$} & \multirow{2}{*}{$\begin{array}{l}\text { Coeficiente } \\
\text { de Variação }\end{array}$} \\
\hline & $5 \%$ & $50 \%$ & $95 \%$ & & & \\
\hline Idade & 20,0 & 31,0 & 50,8 & 33,8 & 9,5 & 9,8 \\
\hline Massa & 56,7 & 65,5 & 85,7 & 67,9 & 8,0 & 6,5 \\
\hline Altura do topo da cabeça & 1,617 & 1,705 & 1,800 & 1,710 & 0,059 & 0,035 \\
\hline Altura do nível dos olhos & 1,496 & 1,586 & 1,694 & 1,596 & 0,062 & 0,039 \\
\hline Altura do ouvido & 1,482 & 1,555 & 1,666 & 1,570 & 0,060 & 0,036 \\
\hline Altura do punho & 0,750 & 0,810 & 0,880 & 0,812 & 0,041 & 0,017 \\
\hline Altura do joelho & 0,450 & 0,480 & 0,526 & 0,482 & 0,021 & 0,049 \\
\hline Altura da espinha ilíaca & 0,895 & 0,958 & 1,050 & 0,959 & 0,047 & 0,022 \\
\hline Altura do tórax & 1,160 & 1,235 & 1,333 & 1,245 & 0,050 & 0,025 \\
\hline Altura apêndice xifóide & 1,111 & 1,195 & 1,288 & 1,190 & 0,053 & 0,028 \\
\hline Altura do umbigo & 0,954 & 1,005 & 1,114 & 1,022 & 0,056 & 0,031 \\
\hline Altura do mento & 1,386 & 1,478 & 1,570 & 1,475 & 0,082 & 0,067 \\
\hline Altura do ombro & 1,329 & 1,418 & 1,519 & 1,425 & 0,055 & 0,030 \\
\hline Altura do cotovelo & 0,976 & 1,050 & 1,139 & 1,055 & 0,047 & 0,022 \\
\hline Altura entrepernas & 0,770 & 0,820 & 0,893 & 0,822 & 0,036 & 0,013 \\
\hline Alcance inferior máximo & 0,540 & 0,623 & 0,696 & 0,621 & 0,041 & 0,017 \\
\hline Alcance inferior pega empunhadura & 0,620 & 0,701 & 0,768 & 0,697 & 0,042 & 0,018 \\
\hline Alcance frontal à extremidade do dedo médio & 0,795 & 0,860 & 0,951 & 0,863 & 0,040 & 0,016 \\
\hline Alcance frontal pega empunhadura & 0,725 & 0,779 & 0,877 & 0,788 & 0,022 & 0,016 \\
\hline Alcance frontal do antebraço à extremidade do dedo médio & 0,449 & 0,470 & 0,525 & 0,476 & 0,034 & 0,053 \\
\hline Comprimento do membro superior & 0,744 & 0,799 & 0,868 & 0,804 & 0,032 & 0,012 \\
\hline Comprimento interarticular do ombro ao cotovelo & 0,288 & 0,313 & 0,346 & 0,314 & 0,018 & 0,035 \\
\hline Comprimento interarticular do cotovelo ao pulso & 0,244 & 0,267 & 0,291 & 0,267 & 0,015 & 0,022 \\
\hline Comprimento interarticular do joelho ao tornozelo & 0,370 & 0,411 & 0,456 & 0,410 & 0,031 & 0,010 \\
\hline Comprimento do pé & 0,250 & 0,265 & 0,292 & 0,269 & 0,017 & 0,031 \\
\hline Largura do pé & 0,100 & 0,110 & 0,125 & 0,110 & 0,006 & 0,046 \\
\hline Largura do quadril & 0,276 & 0,304 & 0,330 & 0,302 & 0,016 & 0,027 \\
\hline Perímetro braquial & 0,249 & 0,283 & 0,325 & 0,286 & 0,022 & 0,049 \\
\hline
\end{tabular}

* Variável idade em anos, massa em kg e demais em m 
Tabela 2. Percentis, média, desvio-padrão e coeficiente de variação do levantamento antropométrico dos operadores (dimensões da mão)

\begin{tabular}{|c|c|c|c|c|c|c|}
\hline \multirow[t]{2}{*}{ Variável Antropométrica } & \multicolumn{3}{|c|}{$\begin{array}{c}\text { Percentis } \\
\text { Encontrados (m) }\end{array}$} & \multirow{2}{*}{$\begin{array}{l}\text { Média } \\
(\mathrm{m})\end{array}$} & \multirow{2}{*}{$\begin{array}{c}\text { Desvio-Padrão } \\
\text { (m) }\end{array}$} & \multirow{2}{*}{$\begin{array}{l}\text { Coeficiente } \\
\text { de Variação } \\
\text { (m) }\end{array}$} \\
\hline & $5 \%$ & $50 \%$ & $95 \%$ & & & \\
\hline Largura da mão no metacarpo & 0,080 & 0,090 & 0,096 & 0,089 & 0,005 & 0,003 \\
\hline Largura da mão no polegar & 0,095 & 0,105 & 0,115 & 0,105 & 0,007 & 0,005 \\
\hline Largura da mão fechada & 0,070 & 0,080 & 0,088 & 0,078 & 0,005 & 0,003 \\
\hline Comprimento da mão na extremidade do dedo médio & 0,169 & 0,195 & 0,216 & 0,191 & 0,017 & 0,028 \\
\hline Comprimento da mão na extremidade do dedo mínimo & 0,142 & 0,155 & 0,170 & 0,156 & 0,008 & 0,007 \\
\hline Comprimento da palma da mão & 0,095 & 0,105 & 0,118 & 0,105 & 0,007 & 0,004 \\
\hline Comprimento da mão na extremidade do polegar & 0,114 & 0,135 & 0,153 & 0,134 & 0,011 & 0,014 \\
\hline Comprimento da mão na base do polegar & 0,055 & 0,068 & 0,077 & 0,067 & 0,007 & 0,004 \\
\hline
\end{tabular}

As medidas antropométricas são estabelecidas em várias faixas, entre o mínimo e o máximo. O uso desses critérios depende do tipo de projeto, das aplicações e da finalidade das medidas.

Observou-se que na empresa existe, com freqüência, troca de função entre os funcionários; portanto, estas variáveis podem ser utilizadas no dimensionamento de postos de trabalho que satisfaçam a esses operadores, porém para um estudo antropométrico completo do operador de motosserra, o recomendado seria estabelecer-se as variáveis relacionadas às dimensões do corpo em movimento com seus ângulos e suas forças envolvidas, com o operador executando seu trabalho com a motosserra. Desta forma, procurou-se relacionar algumas variáveis do levantamento antropométrico estático que possam contribuir para um dimensionamento adequado, tanto da máquina de trabalho quanto da atividade envolvida.

Os resultados da avaliação de algumas variáveis do levantamento antropométrico estático dos operadores de motosserra são apresentados na Tabela 3.

Para a variável massa, Senne (1994) indicou, em sua pesquisa para a atividade de corte florestal com motosserra, recrutar indivíduos fisicamente bem constituídos e com massa corpórea

Tabela 3. Algumas variáveis antropométricas do indivíduo em pé e sua utilização com respectivos percentis indicados (Moraes, 1983)

\begin{tabular}{lcc}
\hline Variável Antropométrica & Utilização & Percentil \\
Indicado (\%)
\end{tabular}

Altura do nível do olho

Altura do ouvido

Altura do punho

Altura do joelho na rótula

Altura da espinha ilíaca

Altura do tórax

Altura do umbigo

Altura do mento

Altura do ombro

Altura do cotovelo

Altura entrepernas

Alcance inferior máximo até a extremidade do dedo médio

Alcance frontal à extremidade do dedo médio

Alcance frontal da mão em pega empunhadura

Alcance frontal do antebraço, até a extremidade do dedo médio

Largura da mão no polegar

Largura da mão fechada

Comprimento da mão na extremidade do dedo médio
Determinação do ângulo superior e inferior de visibilidade nos planos frontal e sagital

Dimensões do suporte de audiofones (por diferença da altura do topo da cabeça) e altura de medição de ruído

Limite inferior proximal da mão, em oposição à extremidade do dedo médio, de modo a se especificar, por soma, os diferentes alcances inferiores

Altura de obstruções a nível do joelho

Definição da altura de vestimenta dos membros inferiores

Definição da altura máxima de comandos a serem acionados, frontal e/ou lateralmente

Localização da altura de obstruções frontais ao nível do abdômen

Em diferença com relação à altura do topo da cabeça, permite dimensionar capacete

Definição da limitação à visibilidade com ombro no plano frontal

Definição da altura de bancadas e consoles para trabalho

Definição da altura de obstruções ao nível da púbis

Altura inferior máxima de comandos

Dimensões para os diferentes alcances frontais,

distâncias horizontais no plano frontal e sagital

Distância horizontal frontal no plano frontal e

sagital (comandos a serem empunhados)

Dimensões para os diferentes alcances frontais, distância horizontal frontal, no plano sagital (comandos com alta freqüência de uso)

Largura mínima para introdução da mão no cabo da motosserra

Profundidade mínima para introdução da mão

no cabo da motosserra Dimensionamento de luvas
$5-95$

5

5

$5-95$

5

5

$5-95$

5

$5-95$

5

5

5

5

5

95

95

$5-95$ 
entre 65,0 e 75,0 kg. Couto (1987) encontrou massa média do operador de motosserra de $68,0 \mathrm{~kg}$.

Couto (1987) estudando a correlação entre massa corpórea e produtividade, concluiu que trabalhadores com massa superior a $68,0 \mathrm{~kg}$ acarretam prejuízo na produtividade, o qual pode ser explicado pela maior dificuldade de movimentos.

$\mathrm{Na}$ Tabela 1 verifica-se que a massa média do operador, para este estudo, foi de $67,9 \mathrm{~kg}$.

\section{Altura do topo da cabeça}

Esta dimensão apresenta grande importância no dimensionamento da altura mínima de passagem (portas), nas obstruções à visibilidade e no vestuário. Esta variável pode ser utilizada como critério na seleção de operadores para o trabalho com motosserra. Os percentis 5, 50 e 95\% apresentaram altura do topo da cabeça, respectivamente, 1,617, 1,705 e 1,800 m.

\section{Comprimento e largura do pé}

Determinação do espaço mínimo no sentido do comprimento e da largura para introdução dos pés. O comprimento do pé na faixa de 25,0 a $29,2 \mathrm{~cm}$ e a largura do pé de 10,0 a $12,5 \mathrm{~cm}$, juntamente com outras variáveis do pé, como perímetros, altura e ângulos, permitem o dimensionamento de calçados, visando à fabricação de equipamentos de proteção individual mais adequados ao perfil do operador da empresa e, conseqüentemente, oferecem maior estabilidade ao trabalhador. As medidas antropométricas estáticas são usadas para dimensionamento de equipamento que exige pouco movimento. Encontram largo emprego no campo de equipamento pessoal, como capacete, máscara, luvas e vestuário.

As dimensões que se referem às extremidades do corpo, separadamente e dentro dos seus limites, são variáveis selecionadas cuja aplicação se destina ao dimensionamento de equipamentos de proteção individual; por exemplo, cabeça (do topo da cabeça ao queixo), mão (do pulso à extremidade do dedo médio) e pé (do calcanhar à extremidade do dedo). $\mathrm{Na}$ Tabela 3, tem-se os percentis que podem ser utilizados para confecção de capacete, luva e peça do vestuário.

As dimensões antropométricas dinâmicas para os quais o operador de motosserra deve aproveitar, do melhor modo possível, os braços e as pernas como sistema de alavanca, executando movimentos, compreendem as seguintes categorias: alcance frontal até a extremidade do dedo médio; alcance frontal da mão em pega empunhadura; e alcance frontal do antebraço até a extremidade do dedo médio; alcance inferior em pega empunhadura. Portanto, essas variáveis dinâmicas devem ser estudadas, pois permitem estabelecer-se variações máximas e mínimas de ângulo entre os diversos elos de ligação que se encontram no centro de articulação do ombro, do cotovelo, da coxa e do joelho do operador, visando definir uma postura de trabalho que melhor atenda ao desempenho da tarefa de corte florestal com motosserra.

Com relação às dimensões da mão, o espaço mínimo para introdução da mão na alça da motosserra, para acionamento e manejo de controles, não deve ser inferior a $0,115 \mathrm{~m}$. A profundidade mínima para introdução da mão entre a parte interna da alça e a proteção inferior da motosserra, não deve ser inferior a $0,088 \mathrm{~m}$.

\section{CONCLUSÕES}

Os dados analisados permitiram as seguintes conclusões:

1. A massa média do operador foi de $67,9 \mathrm{~kg}$.

2. O percentil $50 \%$ apresenta o valor de $1,705 \mathrm{~cm}$, para a variável altura do topo da cabeça.

3. O espaço mínimo para introdução da mão no cabo da motosserra não deve ser inferior a $0,115 \mathrm{~m}$.

4. A profundidade mínima para introdução da mão no cabo da motosserra não deve ser inferior a $0,088 \mathrm{~m}$.

\section{LITERATURA CITADA}

Barros, I.F.R. Fatores antropométricos e biomecânicos da segurança no trabalho: uma contribuição à analise de sistemas homem-máquina sob o ponto de vista da ergonomia. Manaus: Universidade do Amazonas, 1996. 122p.

Couto, H.A. Temas de saúde ocupacional; coletânea dos cadernos da Ergo. Belo Horizonte: Ergo, 1987. 250p.

Iida, I. Ergonomia; projeto e produção. São Paulo: Edgard Blucher, 1990. 465p.

INT - Instituto Nacional de Tecnolocia. Pesquisa antropométrica e biomecânica dos operários da indústria de transformação, RJ. (Medidas para postos de trabalho). Rio de Janeiro: Instituto Nacional de Tecnologia, v.1, 1988. 128p.

Moraes, A. de. Aplicação de dados antropométricos; dimensionamento da interface homem-máquina. Rio de Janeiro: UFRJ, 1983. 522p. Dissertação Mestrado

Senne, J.M. Análise fisiológica e biomecânica da função motosserrista. In: Seminário de atualização sobre sistemas de colheita de madeira e transporte florestal, 8, 1994. Curitiba. Anais... Curitiba: FUPEF/UFPr, 1994. p.1-19. 